\section{Epinephrine Induced Digital Ischemia After Accidental Injection from an Auto-injector Device}

The use of epinephrine auto-injectors for prehospital treatment of severe allergic reactions in children has become increasingly common [1], widely accepted and prescribed [2]; $5 \%$ of the pediatric population in the United Kingdom has some form of food allergy [3].

An 11-year-old girl accidentally injected her right thumb with the EpiPen. This injection caused immediate ischemic changes in the distal right thumb and developed paraesthesia, pain, pallor, prolonged peripheral capillary refill time and cold blue right thumb. Examination of the right thumb revealed a puncture wound centrally on the volar pad. She received warm water immersion and local nitroglycerin paste. A mixture of $0.5 \mathrm{mg}$ of phentolamine, $1.0 \mathrm{~mL}$ of normal saline with $1.0 \mathrm{~mL}$ of $2 \%$ lidocaine was prepared and kept ready for half of this mixture to be infiltrated subcutaneously at the puncture site, and the rest to be infiltrated along the course of the digital arteries should her symptoms worsen or her clinical condition deteriorates. She had an uneventful recovery following a period of observation.

There is a greater incidence of accidental autoinjection into digits [1]. Epinephrine is a sympathomimetic agent and has both $\alpha$-adrenergic and $\beta$ adrenergic responses. Several methods have been tried to reverse the effect of epinephrine accidentally injected into a digit including spontaneous reversal, warm water immersion, systemic or topical nitroglycerin, topical infiltration with terbutaline, topical and /or systemic phentolamine.

Topical infiltration of phentolamine is the most appropriate treatment as it is easy to perform, reverses ischaemia quickly and efficiently, has no reported adverse reactions, and is effective in late presentations [1, 4-5]. Phentolamine, a short acting $\alpha$-blocker used mainly to control blood pressure during surgical resection of phaechromocytoma, has been used as an effective $\alpha$ adrenergic antagonist appropriately. Phentolamine at puncture site, digital block and intra-arterial administration have proved beneficial in reversing the vasoconstrictive effect of epinephrine induced digital ischaemia. However, a further injection may be required to completely restore perfusion.

The most appropriate evidence-based management for this situation was reviewed. If on assessment there is adequate peripheral perfusion of the digit; patient may be discharged. If the peripheral perfusion is compromised, the intradigital sequential administration of phentolamine into the puncture wound and along the course of digital arteries on both sides is the preferred management at any age, and even in delayed cases not responding to conservative management.

$$
\begin{array}{r}
\text { RAMNIK PATEL AND HEMANT KUMAR } \\
\text { Department of Paediatric Surgery, } \\
\text { Directorate of Children's Services, } \\
\text { Univeristy Hospitals of Leicester NHS Trust, } \\
\text { Leicester Royal Infirmary, } \\
\text { Infirmary Square, LeicesterLE15WW, United Kingdom. } \\
\text { patelramnik@rediffmail.com }
\end{array}
$$

\section{REFERENCES}

1. Velissariou I, Cottrell S, Berry K, Wilson B. Management of adrenaline (epinephrine) induced digital ischaemia in children after accidental injection from an EpiPen. Emerg Med J. 2004;21:387-8.

2. Macdougall CF, Cant AJ, Colver AF. How dangerous is food allergy in childhood? The incidence of severe and fatal allergic reactions across the UK and Ireland. Arch Dis Child. 2002;86:236-9.

3. Watura JC. Nut allergy in school children: a survey of schools in the Severn NHS Trust. Arch Dis Child. 2002;86:240-4.

4. Mc Govern SJ, Treatment of accidental digital injection of adrenaline from an auto-injector device. J Accid Emerg Med. 1997;14:379-80.

5. El Maraghy MW, El Maraghy AW, Evans HB. Digital adrenaline injection injuries: a case series and review. Can J Plast Surg.1998; 4:196-200. 